\title{
Henri Alain-Fournier, Le Grand Meaulnes
}

\section{Elisa Borghino}

\section{(2) OpenEdition}

\section{Journals}

\section{Edizione digitale}

URL: http://journals.openedition.org/studifrancesi/6409

DOI: ERREUR PDO dans /localdata/www-bin/Core/Core/Db/Db.class.php L.34 : SQLSTATE[HY000]

[2006] MySQL server has gone away

ISSN: 2421-5856

\section{Editore \\ Rosenberg \& Sellier}

\section{Edizione cartacea}

Data di pubblicazione: 1 novembre 2010

Paginazione: 583

ISSN: 0039-2944

\section{Notizia bibliografica digitale}

Elisa Borghino, «Henri Alain-Fournier, Le Grand Meaulnes», Studi Francesi [Online], 162 (LIV | III) | 2010, online dal 30 novembre 2015, consultato il 08 janvier 2021. URL: http://journals.openedition.org/ studifrancesi/6409 ; DOI: https://doi.org/10.4000/studifrancesi.6409

Questo documento è stato generato automaticamente il 8 janvier 2021.

\section{(c) (i) (9)}

Studi Francesi è distribuita con Licenza Creative Commons Attribuzione - Non commerciale - Non opere derivate 4.0 Internazionale. 


\title{
Henri Alain-Fournier, Le Grand Meaulnes
}

\author{
Elisa Borghino
}

\section{NOTIZIA}

HENRI ALAIN FOURNIER, Le Grand Meaulnes, édition critique par Marie-Hélène BOBLET, Paris, Champion, 2009, pp. 385.

1 Nella nuova edizione critica de Le Grand Meaulnes offertaci da Marie-Hélène Boblet, docente di letteratura francese all'Université Paris III-Sorbonne Nouvelle, la modernità e la complessità del romanzo di Henri Alain-Fournier rivestono un ruolo di primo piano. Tra simbolismo e avventura, le vicende di Augustin Meaulnes e dell'antieroe - e narratore - François Seurel si dipanano sullo sfondo di una Sologne incantata, dove il mistero incorporato nel reale prende vita. Il limitare di infanzia e adolescenza diventa così quello stesso punto di incontro dove poesia e romanzo si fondono e si confondono, in una narrazione volutamente frammentaria: la sapiente architettura del racconto e le trappole tese dall'autore rivelano molto più del già noto, inscindibile binomio di arte $\mathrm{e}$ vita, facendone non solo un romanzo sentimentale, ma anche e soprattutto il racconto iniziatico di un momento artistico e letterario concepito in fondo come un rito di passaggio.

2 Ormai annoverato tra i classici contemporanei della letteratura francese, Le Grand Meaulnes è rappresentativo del nuovo slancio poetico di inizio secolo e dei suoi interrogativi, in una svolta letteraria testimoniata d'altro canto dalla corrispondenza tra Henri Alain-Fournier e Jacques Rivière. Romanzo inaugurale e profetico, che sorpassa il naturalismo e il realismo del secolo precedente, il testo di Alain-Fournier vede i suoi personaggi presi nella continua ed incessante ricerca di un oggetto del desiderio tanto taciuto quanto riconoscibile. Pur non proponendo alcun discorso teorico di inizio secolo, Le Grand Meaulnes si fa comunque portatore di quel romanesque intérieur che trova la sua concretizzazione nell'orizzonte spazio-temporale dell'infanzia. 
Sono d'altronde il concreto e il contingente a trasmettere quella geografia immaginaria capace di trasformare un luogo nell'espressione della coscienza, traducendo in realtà interiore e soggettiva un paesaggio sensibile. Per Marie-Hélène Boblet tre restano comunque gli orientamenti tra cui l'autore spazia e, talvolta, tentenna: dal racconto poetico al romanzo d'avventura, passando per il roman romanesque, la costruzione dinamica e incalzante dell'opera rimanda per certi versi a quelle collisioni accidentali in un mondo accidentale suggerite da Hegel.

3 Completa la presente edizione Champion la ricca appendice costituita da brani estratti dai Miracles e dalla corrispondenza di Alain-Fournier, dove la gestazione del romanzo tra l'altro l'unico compiuto dell'autore - è ripercorsa nei minimi dettagli, il che permette di chiarire alcuni momenti chiave del discorso creativo. 